УДК 628.161.2(571.12)

ИСПОЛЬЗОВАНИЕ ПРОМЫШЛЕННОГО КАТИОНИТА СФ-5

В ПРАКТИКЕ ОЧИСТКИ ПРИРОДНЫХ ВОД ЮГА ТЮМЕНСКОЙ ОБЛАСТИ

Пимнева Л.А., Загорская А.А., Решетова А.А.

тюменский индустриальный университет, Тюмень, е-таil: pimnevala@tyиiи.ru

Статья посвящена проблемам загрязнения поверхностных водоемов юга Тюменской области ионами тяжелых металлов. Устойчивое загрязнение водотоков на юге региона приводит к ухудшению качества питьевой воды в системах централизованного водоснабжения крупных и средних населенных пунктов. Тюменская область является эндемиком по наличию ионов меди, марганца и железа в природной воде, что обусловлено структурой и химическим составом подстилающих грунтов. Эффективные и экономичные методы извлечения ионов меди, марганца и железа из природных и сточных вод позволили бы снизить накопление их в биоте и стагнировать передачу по пищевой цепи, что, несомненно, благотворным образом сказалось бы на здоровье населения. Целью работы стало исследование возможности использования промышленного катионита СФ-5 для снижения концентраций ионов меди, марганца и железа. Для решения поставленной задачи исследовалась сорбция в динамических условиях и кинетика сорбции ионов металлов на модельных растворах при изменении температур в диапазоне от 298 до 333 градусов Кельвина. Определена сорбционная ёмкость промышленного катионита по отношению к ионам меди, марганца и железа, проведено сравнение сорбционной емкости сорбента СФ-5 в $\mathrm{H}^{+}$и $\mathrm{NH}_{4}^{+}$-формах. Рассмотрено влияние постороннего электролита (соляной кислоты) на сорбцию исследуемых ионов металлов. Исследована кинетика сорбции ионов меди, марганца и железа. Установлен внутридиффузионный характер кинетики. Рассчитаны коэффициенты диффузии и значения энергии активации. При выборе и оптимизации условий извлечения, концентрирования и разделения ионов катионитом использовали полученные результаты исследования. Кроме этого, полученные результаты по кинетике ионного обмена используются при расчете и проектировании технологического оборудования с целью интегрирования технологии в существующие в регионе схемы очистки природных и сточных вод.

Ключевые слова: сорбция, катионит, ионы меди, марганца, железа, кинетика сорбции, энергия активации, коэффициенты взаимодиффузии

\title{
THE USE OF INDUSTRIAL CATIONITESF-5 IN THE PRACTICE OF PURIFICATION OF NATURAL WATERS IN THE SOUTH OF THE TYUMEN REGION
}

Pimneva L.A., Zagorskaya A.A., Reshetova A.A.

\author{
Tyumen Industrial University, Tyumen, e-mail:pimnevala@tyuiu.ru
}

\begin{abstract}
The article deals with the problems of pollution of surface waters of the south of the Tyumen region with heavy metal ions. Persistent pollution of watercourses in the south of the region leads to a deterioration in the quality of drinking water in the centralized water supply systems of large and medium-sized settlements. The Tyumen region is endemic for the presence of copper, manganese and iron ions in natural water, which is due to the structure and chemical composition of the underlying soils. Effective and economical methods of extracting copper ions, manganese and iron from natural and wastewater would reduce their accumulation in biota and stagnate transmission through the food chain, which undoubtedly beneficially impact on public health. The aim of the work was to investigate the possibility of using industrial cationit SF-5 in order to reduce the concentration of ions of copper, manganese and iron. To solve the problem, the kinetics of sorption of metal ions was investigated under dynamic conditions on model solutions with temperature variations in the range from 298 to 303 Kelvin. The sorption capacity of industrial cationite with respect to copper, manganese, and iron ions was determined, and the sorption capacity of SF-5 sorbent in $\mathrm{H}^{+}$- and $\mathrm{NH}_{4}^{+}$- forms was compared. The influence of an extraneous electrolyte (hydrochloric acid) on the sorption of the metal ions under study is considered. The kinetics of sorption of copper, manganese, and iron ions is studied. The intradiffusion character of the kinetics is established. The diffusion coefficients and activation energy values are calculated. When selecting and optimizing the conditions for the extraction, concentration and separation of ions with cationite, the results of the study were used. In addition, the obtained results on the kinetics of ion exchange are used in the calculation and design of technological equipment in order to integrate the technology into the existing schemes of natural and wastewater treatment in the region.
\end{abstract}

Keywords: sorption, cationite, copper, manganese, iron ions, sorption kinetics, activation energy, mutual diffusion coefficients

Ежегодный мониторинг состояния поверхностных вод водотоков Тюменской области демонстрирует стабильное ухудшение качества природных вод [1]. Поступление загрязняющих веществ происходит от соседних областей (Свердловской, Курганской, Омской области и Республики Казахстан) в результате миграции веществ [2]. На территории Тюменской области действу- ют около 130 промышленных предприятий и сельскохозяйственных объектов с общим объемом потребления 315,4 млн т воды в год. Стоки поступают в реки и озера, очищенные только на $69,4 \%$. Данные факторы влияют на качество питьевых вод в централизованных системах водоснабжения. Накопление ионов тяжелых металлов приводит к риску возникновения целого ряда 
заболеваний [3]. В связи с этим снижение концентрации ионов металлов в природных и сточных водах Тюменского региона является важной экологической задачей. Концентрация ионов тяжелых металлов в водных объектах представлена на рис. 1 .

Для обезвреживания сточных вод используют сорбционный метод с применением промышленных сорбентов. Этот метод позволяет очищать загрязненные воды до любой остаточной концентрации $[4,5]$. Промышленные сорбенты представляют собой органические смолы, имеющие в своем составе ионообменные или комплексообразующие функциональные группы.

Целью данной работы является исследование сорбционных характеристик катионита СФ-5 по отношению к ионам меди, марганца и железа, изучение кинетики сорбции.

\section{Материалы и методы исследования}

Исследования проводились на макропористом катионите СФ-5 с обменной емкостью 7,92 мг-экв/Г и размером зерен в воздушно-сухом состоянии 0,25-0,5 мм. Кислотные свойства катионита СФ-5 характеризуются показателями кажущихся констант ионизации $\mathrm{pK}_{1}=3,1$ и $\mathrm{pK}_{2}=8,4$. Изучали сорбцию меди (II), марганца (II) и железа (III) из модельных растворов в динамических условиях в колонках сечением 1,4 см³. Масса катионита в колонке была 6 г. Скорость фильтрации всех растворов при сорбции равнялась $1 \mathrm{мл} / \mathrm{cm}^{3} \cdot$ мин. Фильтрат растворов отбирался по 25 мл.

Кинетику ионного обмена изучали методом ограниченного объема индивидуальных растворов меди, марганца и железа (III). В водяной термостат помещали ем- кость с раствором при соотношении жидкой и твердой фаз Ж:Т = 1:1000 и температурах 298, 313 и 333 К. Перемешивание раствора осуществлялось механической мешалкой со скоростью 150 об/мин. Суммарный объем отобранных проб от исходного объема раствора не превышал $3 \%$.

\section{Результаты исследования и их обсуждение}

Сточные воды имеют $\mathrm{pH}$ 2-5, поэтому использовали подкисленные соляной кислотой растворы. Зависимость величины емкости обмена меди (II), марганца (II) и железа (III) от концентрации соляной кислоты при сорбции катионитом СФ-5 в водородной и солевой формах показана на рис. 2 . Емкость обмена с увеличением концентрации соляной кислоты уменьшается. При этом количество сорбируемых ионов для солевой (аммонийной) формы катионита выше по отношению к водородной форме. При этом сорбция ионов железа превышает обменную емкость катионита.

Результаты, представленные на рис. 3, свидетельствуют о параллельном переносе фронта сорбции. Скорость движения стационарного фронта является постоянной.

Полученные результаты исследования сорбции ионов меди, марганца и железа (III) использовали для выбора условий их извлечения, концентрирования и разделения с помощью катионита СФ-5. Разделение ионов меди и железа (III), марганца и железа (III) происходит уже на стадии совместной сорбции, что наглядно показано на рис. 4. В эксперименте использовали навеску катионита 6 г, количество сорбированных ионов по 5 мг-экв и скорость фильтрации раствора $1 \mathrm{мЛ} / \mathrm{cm}^{2} \cdot$ Мин.

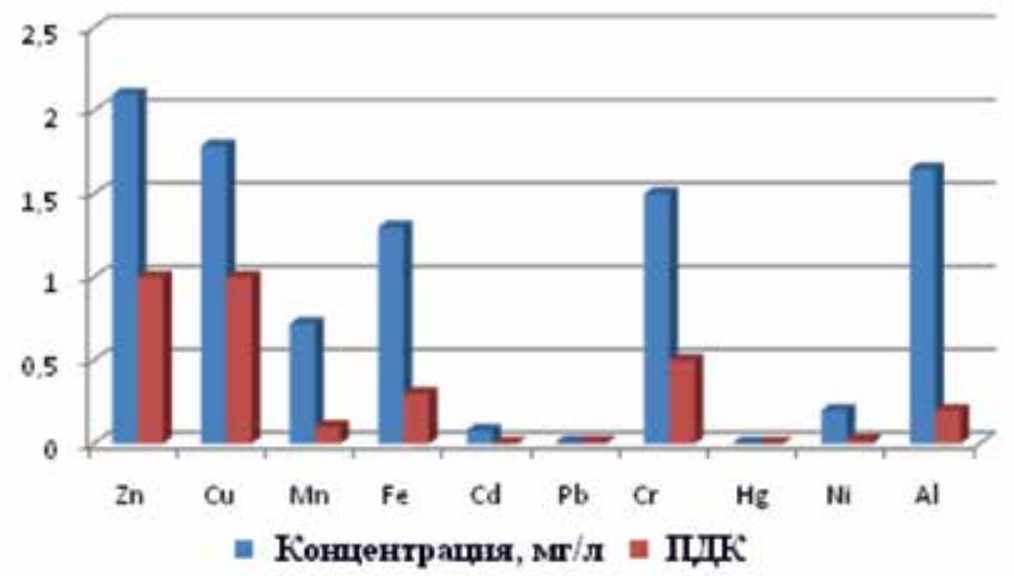

Рис. 1. Концентрация тяжельх металлов в водных объектах Тюменской области 

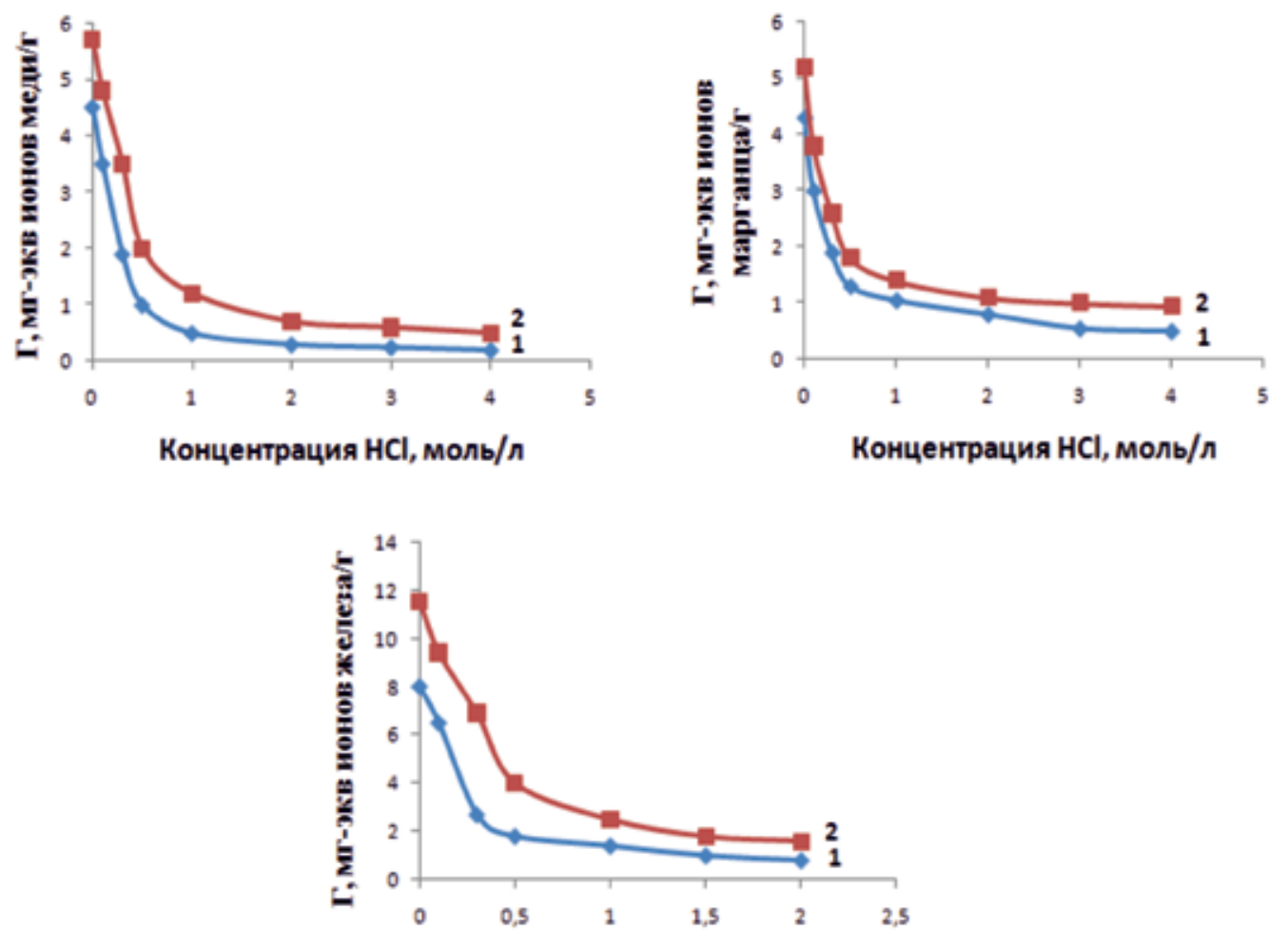

Концентрация $\mathrm{HCl}$, моль/л

Рис. 2. Влияние конщентращии соляной кислоть на величину сорбции
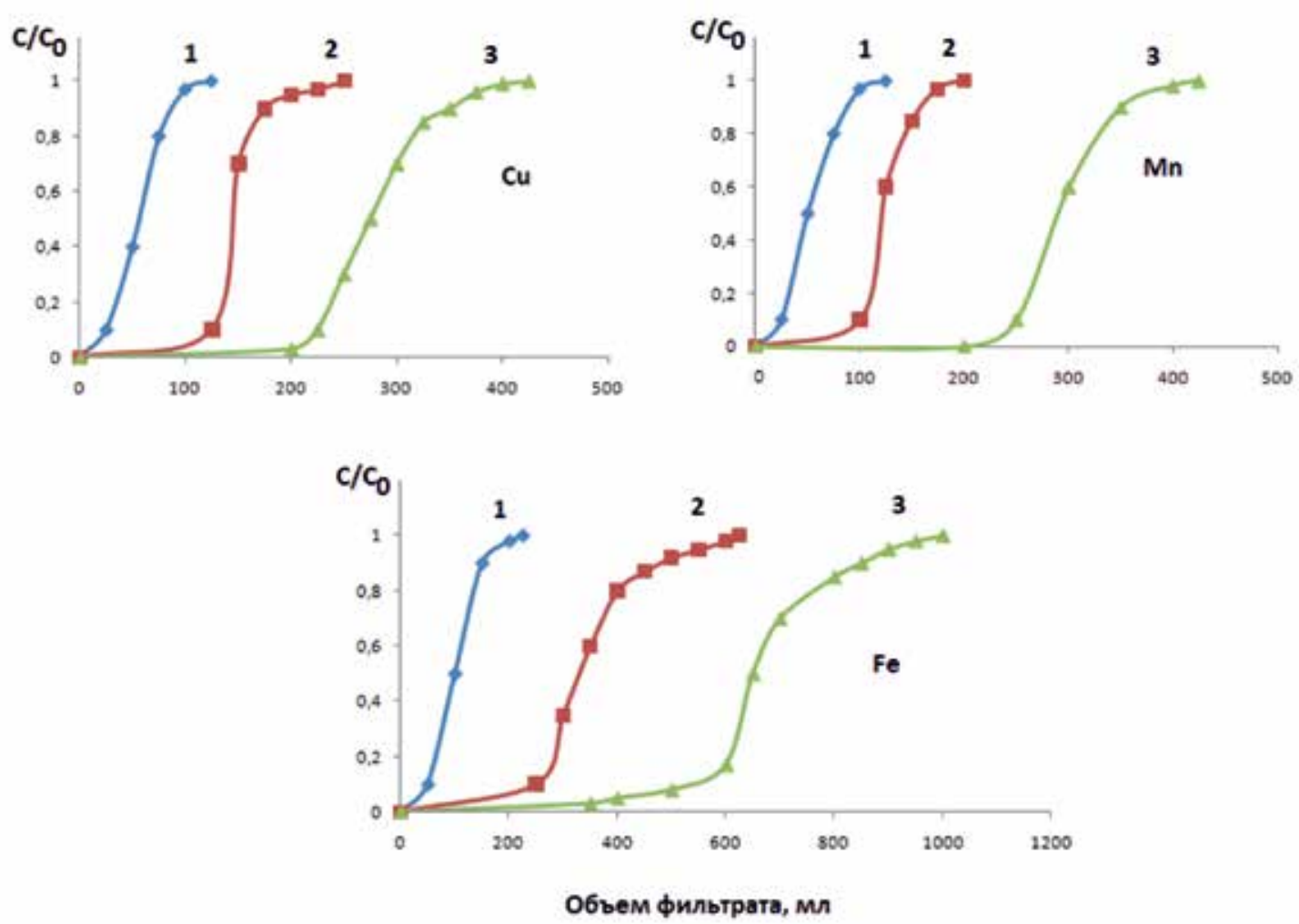

Рис. 3. Кривые сорбции исследованных металлов на 1,0 (1), 3,0 (2), 6,0 (3) г катионитом СФ-5 


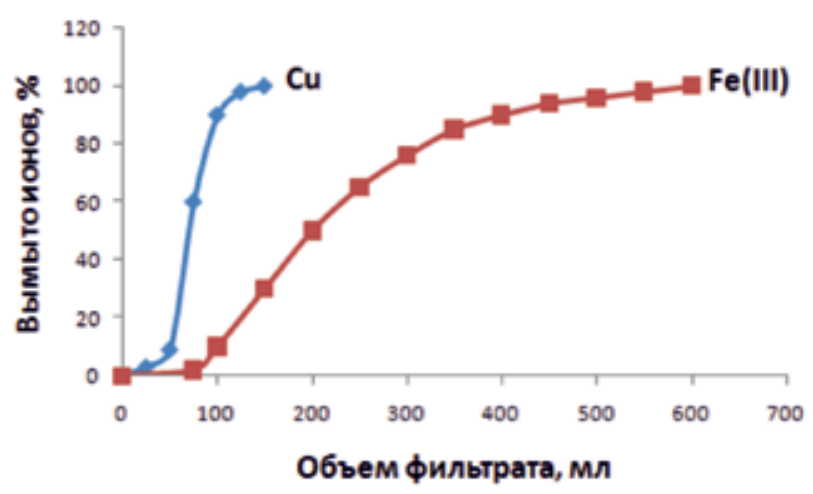

Рис. 4. Разделение ионов меди и железа после совместной сорбции на катионите СФ-5

Выбор технологического режима при извлечении загрязняющих веществ процесса сорбции характеризуется кинетическими параметрами. Полученные экспериментальные данные обрабатывали с использованием уравнения [6]:

$$
F=1-\frac{6}{\pi} \sum_{n=1}^{\infty} 1 / n^{2} \exp \left(-\frac{D \cdot \pi^{2} \cdot n^{2} \cdot t}{r^{2}}\right),
$$

где $F$ - степень достижения равновесия; $D$ - коэффициент диффузии, $\mathrm{cm}^{2} / \mathrm{c} ; r-$ paдиус зерна катионита, мм; $t$ - время, с; $F=\frac{D \cdot \pi^{2} \cdot t}{r^{2}}=B t-$ безразмерный параметр или критерий гомохронности Фурье.

Кинетические кривые сорбции ионов металлов приведены на рис. 5. На примере ионов меди показано увеличение скорости сорбции ионов при повышении температуры. Зависимость $B t=f(t)$ имеет линейный вид, что подтверждает лимитирующую стадию диффузии в фазе сорбента [6].

Зависимость коэффициента внутренней диффузии от температуры выражается уравнением

$$
\lg \bar{D}=\lg \bar{D}_{0}-\Delta E / R T,
$$

где $\Delta E$ - энергия активации суммарного диффузионного процесса, $\bar{D}_{0}-$ предэкспоненциальный множитель.

Скорость диффузии ионов металлов в фазе катионита будет зависеть от следующих факторов: размеров гидратированных ионов, их зарядов и подвижности. Радиусы гидратированных ионов увеличиваются от меди к железу

$$
\mathrm{Cu}^{2+}(4,19)>\mathrm{Mn}^{2+}(4,38)>\mathrm{Fe}^{3+}(4,57) .
$$

Скорость внутренней диффузии по значениям коэффициента диффузии возрастает от железа к меди.
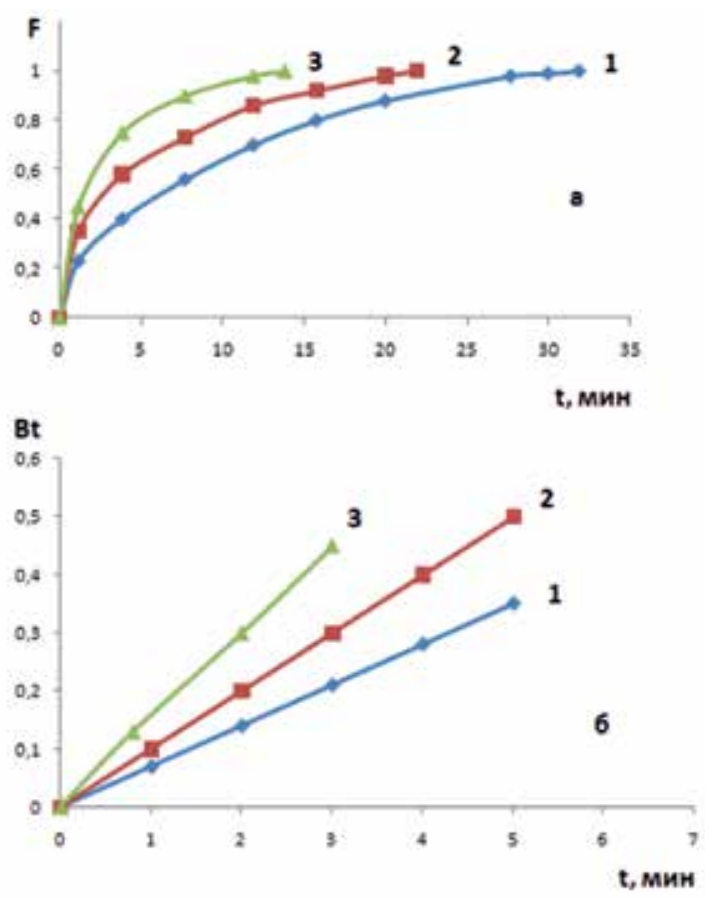

Рис. 5. Кинетические зависимости (а) u зависимость Bt от t при сорбиии ионов меди катионитом СФ-5 в $\mathrm{H}^{+}$-форме

Энергия активации для исследованных ионов не превышает значений, характерных для диффузионных процессов.

\section{Заключение}

Проведение сравнительных сорбционных данных в динамических условиях показывает, что катионит СФ-5 позволяет эффективно очищать раствор от исследованных ионов. 
Значения коэффициентов внутренней диффузии и энергии активации процесса сорбции

\begin{tabular}{|c|c|c|c|c|}
\hline \multirow[t]{2}{*}{ Катион } & $\bar{D} \cdot 10^{8}$ & \multicolumn{2}{|c|}{ при температуре (К) } & \multirow[t]{2}{*}{$\Delta \mathrm{E}$, кДж/моль } \\
\hline & 298 & 318 & 333 & \\
\hline \multicolumn{5}{|c|}{$\mathrm{H}^{+}$-форма } \\
\hline $\mathrm{Cu}^{2+}$ & 9,2 & 11,8 & 22,1 & 16,0 \\
\hline $\mathrm{Mn}^{2+}$ & 8,9 & 11,8 & 19,7 & 17,6 \\
\hline $\mathrm{Fe}^{3+}$ & 1,2 & 3,3 & 5,9 & 32,8 \\
\hline \multicolumn{5}{|c|}{$\mathrm{NH}^{+}$-форма } \\
\hline $\mathrm{Cu}^{2+}$ & 11,8 & 18,5 & 36,9 & 16,1 \\
\hline $\mathrm{Mn}^{2+}$ & 7,4 & 9,8 & 22,1 & 22,8 \\
\hline $\mathrm{Fe}^{3+}$ & 2,7 & 5,0 & 9,9 & 26,4 \\
\hline
\end{tabular}

Скорость определяющей стадией процесса сорбции ионов меди, марганца и железа является внутренняя диффузия. По значениям коэффициентов внутренней диффузии скорость сорбции уменьшается от меди к железу:

$$
\mathrm{Cu}^{2+}<\mathrm{Mn}^{2+}<\mathrm{Fe}^{3+}
$$

При выборе и оптимизации условий извлечения и разделения ионов можно использовать полученные кинетические параметры.

\section{Список литературы / References}

1. Жиляков Е.В., Монахова 3.Н., Гузеева С.А., Брюханова Р.Я., Томус И.Ю. Анализ геоэкологической ситуации в водных объектах Тюменской области и города Тюмени // Успехи современного естествознания. 2019. № 5. С. 47-52.

Zhilyakov E.V., Monakhova Z.N., Guzeeva S.A., Bryukhanova R.Ya., Tomus I.Yu. Analysis of the geoecological situation in the water bodies of the Tyumen region and the city of Tyumen // Uspekhi sovremennogo yestestvoznaniya. 2019. No. 5. P. 47-52 (in Russian).

2. Отчет об экологической ситуации в Тюменской области в 2018-2019 гг. Правительство Тюменской области. Тюмень, 2020. 211 c.

Report on the environmental situation in the Tyumen region in 2018. 2019. Government of the Tyumen region. Tyumen, 2020. 211 p. (in Russian).
3. Доклад о состоянии здоровья населения и организации здравоохранения в Тюменской области по итогам деятельности за 2019 год. ГАУТО «Медицинский информационно-аналитический центр», 2020. 79 с.

Report on the state of health of the population and the organization of health care in the Tyumen region based on the results of activities for 2019. GAU TO «Medical Information and Analytical Center», 2020. 79 p. (in Russian).

4. Скороходов В.Ф., Месяц С.П., Остапенко С.П. Решение проблемы очистки сточных вод промышленных предприятий от многокомпонентных загрязнений // Горный журнал. 2010. № 9. С. 106-108.

Skorokhodov V.F., Monet S.P., Ostapenko S.P. Solution of the problem of industrial wastewater treatment from multicomponent pollution// Gornyy zhurnal. 2010. No. 9. P. 106108 (in Russian).

5. Николаева Л.А., Исхакова Р.Я. Ресурсосбережение в технологии очистки сточных вод промышленных предприятий // Энергоресурсоэффективность и энергосбережение: сб. науч. трудов. Казань: ТаГраф, 2014. С. 102-106.

Nikolaeva L.A., Iskhakova R.Ya. Resource saving in the technology of wastewater treatment of industrial enterprises // Energoresurso-effektivnost' i energosberezheniye: sb. nauch. Tr. Kazan': TaGraf, 2014. P. 102-106 (in Russian).

6. Тимофеев К.Л., Усольцев А.В., Краюхин С.А., Мальцев Г.И. Кинетика сорбции ионов индия, железа и цинка слабокислотными катионитами // Сорбционные и хроматографические процессы. 2015. Т. 15. Вып. 5. С. 720-729.

Timofeev K.L. Usoltsev A.V., Krayukhin S.A., Maltsev G.I. Kinetics of sorption of indium, iron, and zinc ions by weakly acidic cationites// Sorbtsionnyye i khromatograficheskiye protsessy. 2015. Vol. 15. Is. 5. P. 720-729 (in Russian). 